\title{
Diversity of Rice: In aspects of Nutritional, Medicinal and Water saving Agriculture
}

\author{
Anjali Dahiya* and Ritu Saini \\ Department of Chemistry and Biochemistry, CCS Haryana Agricultural University, Hisar, Haryana, India
}

\begin{abstract}
Rice (Oryza sativa L.) is the staple food for people worldwide. Rice cultivation is one of the most vital agricultural activity on earth, almost $90 \%$ of Rice being produced in Asia. It is an annual grass of family Gramineae, subfamily Oryzoidea and belongs to genus Oryza. Rice is the seed of the monocot plants. It occupies one fifth of the total land covered under cereal crops. Rice is very nutritious and more than two-thirds of the world's population who depends on the nutritional and medicinal benefits of rice. Moreover, rice as a model crop with fully sequenced genome, relatively small genome size, significant level of polymorphism and large amount of well conserved genetically diverse material, gives unique opportunities to researcher for studying its varietal difference and history of crop improvement using different approaches like development of water saving technology i.e. aerobic rice.
\end{abstract}

Keywords: Rice, Nutrition, Aerobic and Medicinal

\section{Production of Rice in India}

\section{Introduction}

Rice production in india is an important part of national economy. India is one of world's largest producers of white and brown rice accounting for $20 \%$ of all world rice production. Principal crops of india are Rice, Wheat, Maize, Coarse cereals and Pulses. Indian Cereal production was 245.5 million tonnes in 2014. Both Wheat (96 million tonnes) and Rice (106.5 million tonnes) were produced in india as shown in Fig. 1. Three largest Rice producing states of India are West Bengal, Uttar Pradesh and Andhra Pradesh producing $15.31,14.63,13.03$ respectively (Fig. 2) (Ministry of Indian agriculture 2014).

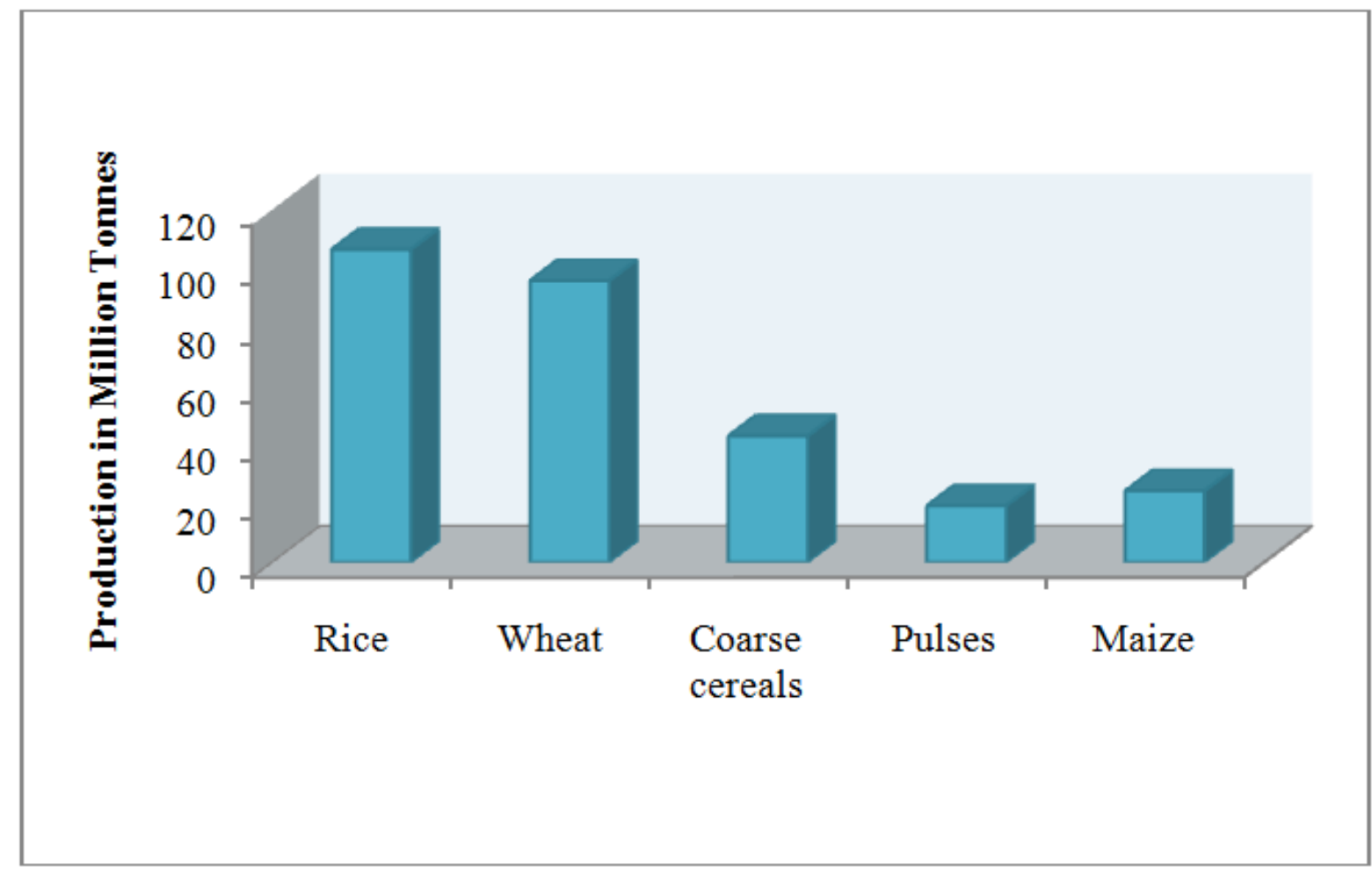

Fig.1 Production of Principal Crops in India during 2014 


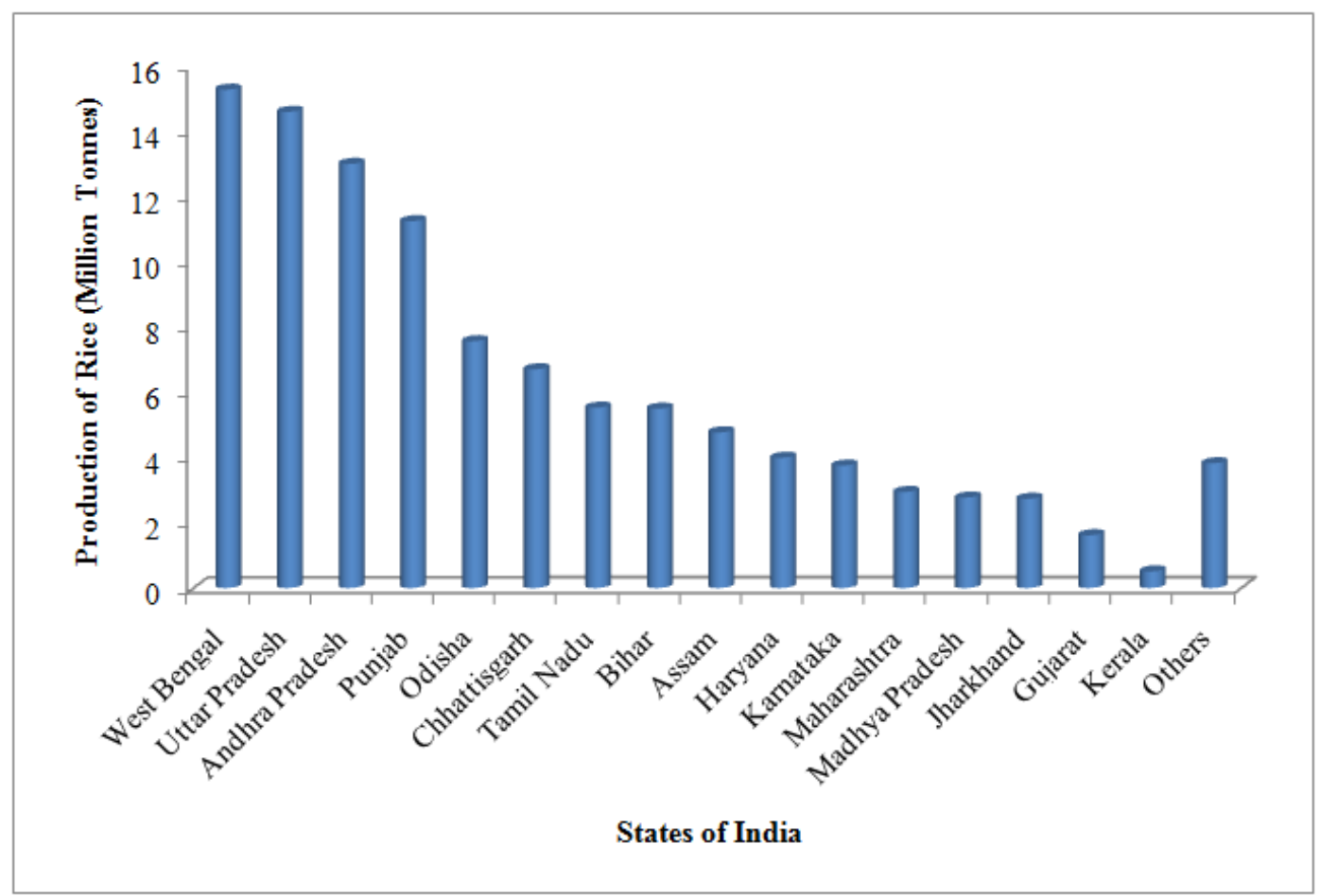

Fig.2 Production of Rice during 2014 in major producing states of India

\section{Nutritional Values of Rice}

Rice is very nutritious and an excellent source of carbohydrates which is an important source of the body fuel, are broken down to glucose, most of which is used as energy for exercise and as essential fuel for the brain. So, it is an excellent food to included in a balanced diet. It is also a good source of vitamins such as thiamine, niacin, iron, riboflavin, vitamin D and minerals like calcium and fiber (Umadevi et al., 2012). All rice is gluten free, making rice the essential choice for Celiac disease patients with gluten free dietary requirements. It has no additives or preservatives. It is a good source of protein, has no fat, no cholesterol and no sodium (Fig.3) containing food for those people who are suffering with hypertension.

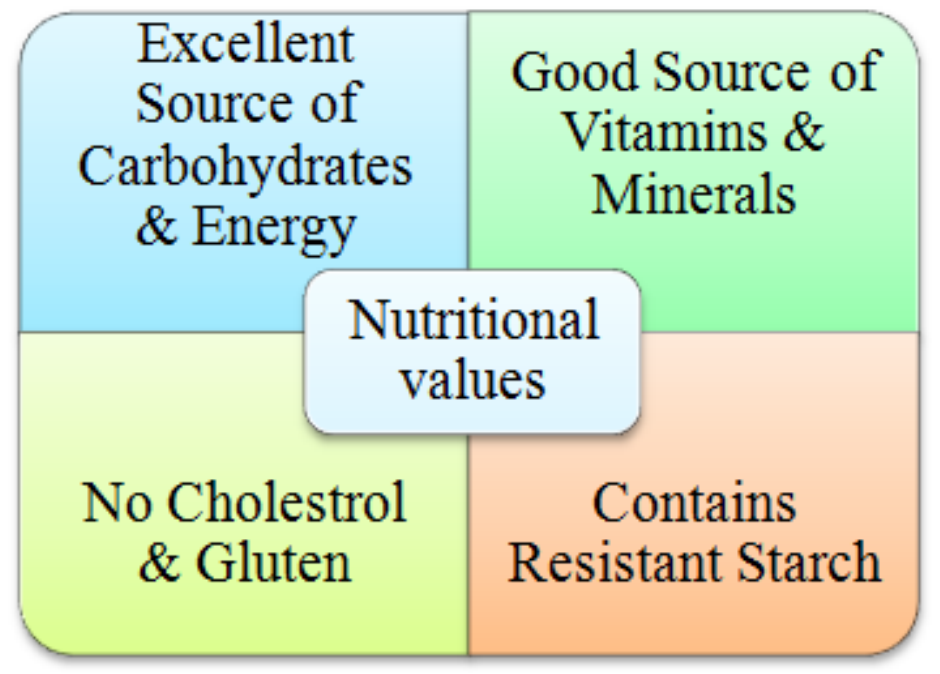

Fig.3: Nutritional Benefits of Rice

\section{Medicinal values of Rice}

The slogan 'Rice is Life' is more suitable as this crop plays a very important role in Indian national food security and mostly rural people's livelihood rely on it. India has a wealth of medicinal plants, most of which have been traditionally used in Ayurveda, Unani Systems of Medicine and by tribal healers for generations. In ancient Indian literature, it is mentioned that every plant on this earth is useful for human beings, animal and for other plants. The medicinal values of rice have been described in Ayurveda. Njavara is an 
upland (grown in hilly areas) crop and has low yield and is found to be moderately resistant to pests and is used mainly for ayurvedic treatments. It plays a vital role in the treatment of various diseases like arthritis, cervical spondylitis, muscle wasting, skin diseases and certain neurological problems. Dehusked seeds of Njavara had relatively high protein, fibre, minerals and vitamins, compared to the non-medicinal varieties (Deepa et al., 2008). These properties could be responsible for its usage as a vehicle, to facilitate the transfer of bioactive compounds from medicinal herbs. Another medicinal rice variety "Laicha" was so named because of its unique property to prevent "Laicha" disease (skin infection) (Umadevi et al., 2012). Karanga rice variety is given to dysenteric patients in Bihar and Jharkhand. In Chhattisgarh, Karhaini variety is used for curing paralysis. Gathuan grain is useful in treatment of rheumatism (Rahman et al., 2006). Nagkesar useful for persons troubled with lung diseases. Inhalation of fumes of Baisoor rice bran is useful to cure headache, hemicrania and epilepsy (Fig.4).

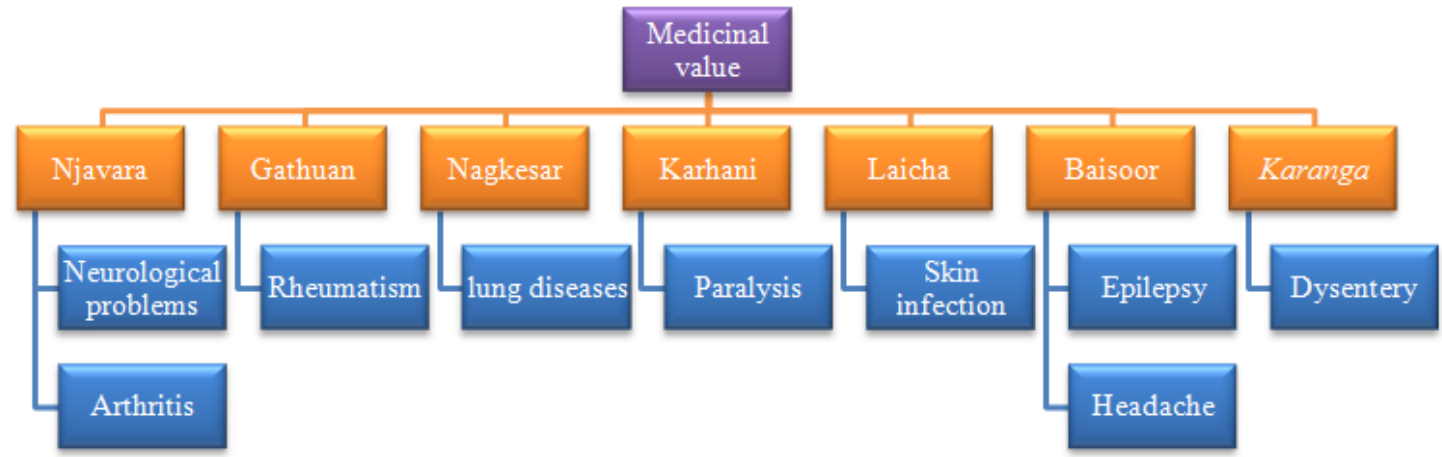

Fig.4: Medicinal benefits of different Rice varieties (Orange shapes represent Indian Rice varieties and blue shapes represent their respective treatment of diseases.)

\section{Aerobic Rice: Water Saving Agriculture}

Due to disproportion between the supply and demand for water sources in a geographical area causes water shortage. In Asia almost $84 \%$ of the water is used for agricultural purposes, compared to $71 \%$ for the world (IRRI). More than 50 per cent of the water is used for rice irrigation in Asia. It takes 3000- 5000 liters of water for producing one $\mathrm{kg}$ of rice, which is 2-3 times higher than required for other cereals like wheat and maize that causes overexploitation of groundwater which is a serious problems in many parts of India (Bouman and Tuong, 2001). Therefore, farmers and researchers are looking for ways to decrease water use in rice production and increase its use efficiency (McCouch et al., 2001).

The majority of the world's rice is being produced under flooded lowland conditions. Of the roughly 147 million ha of rice land, 79 million ha are classified as irrigated lowland, 36 million ha as rain-fed lowland, and 13 million ha as flood-prone (IRRI) (Fig.5).

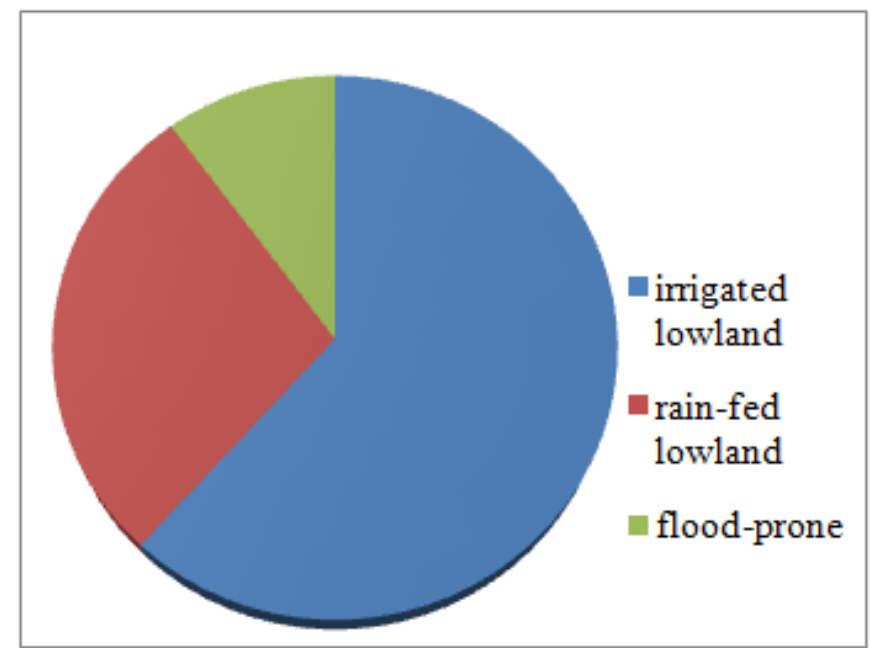

Fig. 5: Area used for production of rice under different conditions.

Several strategies are being used for reducing water consumption for rice cultivation, such as saturated soil culture on raised beds, alternate wetting and drying, ground cover system, system of rice intensification and 
aerobic rice cultivation. Of these strategies, aerobic rice is considered to be one of the most promising strategies in terms of water-saving (Bouman et al., 2006).

Traditionally, rice has been grown under water-limited (non flooded), aerobic soil conditions in uplands for centuries, but average yields are low (1-2 t/ha), because of adverse environmental conditions (poor soils, little rainfall, weeds), low use of external inputs, and low yield potential of upland rice cultivars. Recently, water efficient 'aerobic rice' varieties have been developed by combining the drought-resistant characteristics of these upland varieties with the high-yielding traits of lowland varieties (Gowada et al., 2011). Aerobic rice is a production system in which specially developed varieties are grown in well-drained, non-puddled and nonsaturated soils. The soil is therefore "aerobic" throughout the growing season, as compared to lowland flooded fields, which are "anaerobic." In India, the development of aerobic rice varieties was initiated at University of Agricultural Sciences, Bangalore in early 1980 using the available upland paddy and high yielding germplasm and several aerobic rice genotypes were developed using conventional breeding and marker-assisted selection techniques in combination.

Aerobic rice requires less quantity of seed, less labour, and saves up to $70 \%$ less water. Aerobic rice shows efficient fertilizer utilization, less incidences of pests/diseases, reduced methane emission, profuse rooting and high tillering, less lodging and high grain and fodder yield, retention of soil structure and quality, etc. Water is further saved because of the absence of continuous seepage, percolation and water evaporation from the ponded water. Thus, aerobic cultivation is not only environment-friendly but also saves time, labor, money and water.

\section{References}

[1]. Ministry of Indian agriculture. (2014). Agricultural statistics at a glance. Oxford press

[2]. Bouman, B.A.M., Tuong, T.P. Field water management to save water and increase its productivity in irrigated rice, Agricultural water management. 49(1), 2001, 11-30.

[3]. Bouman, B.A.M., Xiaogaung, Y., Hauqi, W., Zhimin, W., Junfang, Z., Bin, C. Performance of aerobic rice varieties under irrigated conditions in North China, Field Crops Research. 97, 2006, 53-65.

[4]. Deepa, G., Singh, V., Akhilender, N.K. Nutrient composition and physicochemical properties of Indian medicinal rice - Njavara, Food Chemistry. 106, 2008, 165-171.

[5]. Gowada, V.R.P., Henry, A., Yamauchi, A., Shashidhar, H.E., Serraj, R. Root biology and genetic improvement of drought avoidance in rice, Field Crops Research. 122, 2011, 1-13

[6]. IRRI (international Rice Research Institute) (1997). Rice almanac, $2^{\text {nd }}$ ed. P.181.IRRI, Los Banos, Phillipines.

[7]. McCouch, S.R., Temnykh, S., Lukashova, A., Coburn, J., DeClerck, G., Cartinhour, S., Harrington, S., Thomson, M., Septiningsih, E., Semon, M., Moncada, P., Li, J. Microsatellite markers in rice: abundance, diversity and applications. In Rice Genetics IV IRRI, Los Banos, Manila, Phillipines, Science Publishers, Inc., New Delhi, India. 2001, 117-135.

[8]. Rahman, S., Sharma, M.P.' Sahai, S. Nutritional and medicinal values of some indigenous rice varieties, Indian Journal of Traditional Knowledge. 5(4), 2006, 454-458.

[9]. Umadevi, M., Pushpa1, R., kumar, K.P., Bhowmik, D. Rice-Traditional Medicinal Plant in India, Journal of Pharmacognosy and Phytochemistry. 1, 2012, 6-12. 